\title{
LAS COMPLEJIDADES PARA UN NUEVO PACTO ENTRE EL CENTRO Y LA IZQUIERDA EN CHILE*
}

\author{
Ernesto Águila Z. \\ Universidad de Chile
}

\begin{abstract}
RESUMEN: El autor observa que la unión estratégica entre centro e izquierda atraviesa una crisis. Mientras el centro, tradicionalmente asociado al socialcristianismo, ha perdido adeptos, la izquierda — argumenta - ha crecido, pero al mismo tiempo se ha fragmentado como nunca en su historia. Entre sus muchas tareas, las izquierdas deben readecuar su interpretación de la sociedad actual, establecer fines comunes y recuperar las confianzas al interior de sus nuevas élites. Estas confianzas requieren reconstruirse también con el centro, en la realidad de una clase media protagónica y un nuevo sistema electoral.

PAlabras Clave: centro, izquierdas, centroizquierda, transición, crisis, confianza.
\end{abstract}

\section{THE COMPLEXITIES ON THE WAY TO A NEW PACT BETWEEN THE CENTRE AND LEFT IN CHILE}

ABSTRACT: The author observes that the strategic union between the centre and the left is going through a crisis. While the centre, traditionally close to the Catholic social teaching, has lost followers, the left-he argues-has grown but at the same time fragmented as never

Ernesto Águila Z. Psicólogo de la Pontificia Universidad Católica y doctor por la U. de Barcelona. Profesor de la Facultad de Filosofía y Humanidades de la U. de Chile. Email: eaguila@uchile.cl.

* Versión revisada de la conferencia presentada en el Centro de Estudios Públicos el miércoles 4 de julio de 2018, con ocasión de la segunda parte del seminario "La centroizquierda en Chile. ¿Cómo se llegó a esto? ¿Cómo se sale?”. 
before in its history. Among the many tasks ahead of them, the different strands of the left have to renew their interpretation of today's society, set common goals and restore trust within their new elites. Trust also needs to be rebuilt with the centre, considering the reality of an assertive middle class and a new electoral system.

KEYWORDS: centre, left, centre-left, transition, crisis, trust.

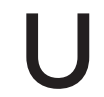

na de las lecciones que extrajo la izquierda - o una parte mayoritaria de ella - de la derrota del proyecto de la Unidad Popular fue que no se podían realizar transformaciones económicas y sociales significativas sin contar con una mayoría política y social. En términos sociales, ello significaba, en esos convulsos años setenta, una alianza entre los trabajadores y las capas medias, y en términos políticos, un acuerdo entre la izquierda y la Democracia Cristiana (DC). La conclusión fue que en ambas asignaturas se había fracasado.

Esta idea de construcción de mayorías y de una unidad de la izquierda con el centro se fue abriendo paso, no sin dificultades, desde fines de los años setenta hasta hacerse hegemónica a fines de los ochenta. Estuvo a la base de la creación de la Concertación de Partidos por la Democracia, dominó el fin de la dictadura y el comienzo de la transición, así como los cuatro gobiernos de la Concertación (1990-2010), y persistió como idea-fuerza en la conformación de la Nueva Mayoría (2014-2017).

No pareciera que hoy esté en discusión la premisa de la necesidad de un acuerdo entre la izquierda y el centro, pero se han producido cambios de tal envergadura que la sola invocación de este objetivo es insuficiente. Luego de la derrota en las elecciones del 17 de diciembre de 2017 se ha abierto un escenario para la centroizquierda de desunión $\mathrm{y}$ dispersión que tiene, a mi juicio, condicionantes estructurales que complejizan una reedición de este acuerdo en el corto y mediano plazo. No se trata de dificultades insalvables, pero tienen aspectos inéditos, o de lo que podríamos denominar un nuevo comienzo.

Estas dificultades podríamos ordenarlas en tres grandes ejes temáticos:

a) Transformaciones políticas, sociológicas y culturales en los espacios del centro político y de la izquierda. Cuando hoy decimos "centro" o "izquierda", estamos hablando de nuevos actores o de cambios 
significativos de lo que esas categorías representaban a comienzos de los noventa y, ciertamente, antes del 73.

b) Un agotamiento del programa transicional, aquel que dominó en los cuatro gobiernos de la Concertación, y de la manera de entender y valorar las formas y cultura política que allí se fraguaron.

c) Una configuración de fuerzas políticas en la que varias de éstas consideran que su alianza con otras más bien les resta que les suma posibilidades de desarrollo futuro, lo que, unido al tránsito del sistema electoral binominal a uno proporcional, genera incentivos para los "caminos propios". Se observan también recambios y desplazamientos elitarios todavía en curso.

Como corolario de estos factores, señalaremos como una de las dificultades más importantes la existencia de una ruptura o falta de confianza entre los actores que conforman hoy el mundo de la centroizquierda.

Veamos brevemente cada uno de estos factores.

En el plano de los actores políticos, el centro constituye hoy un espacio en acelerada transformación. Este espacio, dominado por décadas por la DC, hoy encuentra a dicho partido en una declinación electoral y política pronunciada, quizás irreversible. Sus dificultades no provienen sólo de una pérdida electoral, la que podría ser circunstancial, sino que también de una mutación del espacio social y cultural que históricamente ocupaba. La pérdida de peso y prestigio de la iglesia Católica la impacta directamente, así como un proceso de secularización de la sociedad chilena, que se traduce en un mayor liberalismo en la esfera de las costumbres y en una mayor valoración de la autonomía moral de las personas. En este sentido, el declive de la DC puede corresponder con un cambio estructural del tradicional espacio de centro, desde una impronta socialcristiana a una más laica y liberal. El socialcristianismo puede sobrevivir - dividido quizás en un ala de derecha y otra de centroizquierda-, pero ya no es evidente que sea la fuerza dominante o exclusiva la que ocupe y hegemonice el centro político chileno.

Por su parte, la izquierda no experimenta una declinación electoral, sino más bien un incremento, pero en un contexto de gran fragmentación. La emergencia de nuevas izquierdas, aglutinadas en el Frente Amplio (FA), coexiste hoy de manera competitiva con la izquierda histórica. La izquierda en Chile ha sido siempre plural, pero no se recuerda 
un grado de fragmentación como el actual. Con propiedad, podemos hablar de un archipiélago de la izquierda. El clivaje no es sólo entre una izquierda emergente y una izquierda histórica, sino que además contiene un componente generacional muy significativo. Hoy debemos hablar más bien de "izquierdas" que de izquierda; se trata de un espacio en transformación, donde todavía no se desarrollan síntesis identitarias como para encontrar un denominador común. El problema, por tanto, no es sólo la unidad de la izquierda con el centro, sino que también el de la unidad de estas izquierdas; esto es, el de superar su excesiva fragmentación.

Como telón de fondo de esta nueva configuración de actores políticos en la centroizquierda, está el proceso de transformación social y cultural de aquellos sectores sociales que tradicionalmente ellos representaron: las clases trabajadoras, populares y las capas medias. En términos generales, esta base social ha venido sufriendo una transformación, desde hace varias décadas, en correspondencia con la organización económica neoliberal del país. Ha disminuido el peso de la clase obrera tradicional; han crecido los empleos asalariados en la esfera de servicios, los independientes y por cuenta propia; ha disminuido el peso de la clase media asociada al Estado; han surgido nuevas capas medias vinculadas al mundo privado. Existe una amplia base social que sobrevive con bajos salarios y pensiones, compelida a buscar su integración por la vía del mercado, del crédito y del endeudamiento.

La conflictividad social no ha desaparecido de nuestra sociedad, pero ha ido cambiando como lo demuestra lo ocurrido el año 2011, como también la emergencia de otros movimientos sociales (NO + AFP, medioambientales, territoriales, etcétera). Se observa más movilización que asociatividad, y una búsqueda de soluciones cotidianas en las que conviven acciones solidarias con otras de fuerte acento individual. Se entremezcla de una manera compleja de descifrar un cierto individualismo posesivo con una nostalgia de comunidad y de un "nosotros". En síntesis, existe una composición material distinta y nuevas subjetividades en el mundo asalariado y en las capas medias, sobre las cuales la izquierda y el centro no tienen aún un diagnostico ni un análisis suficientemente acabados y comprensivos. La incomprensión de estas lábiles y ambivalentes nuevas subjetividades sociales es un elemento esencial de la dificultad que tiene la centroizquierda para poder reconectarse con la sociedad en términos electorales y culturales. 
En definitiva, cuando hoy hablamos de izquierda y del centro y de la posibilidad de su unión, encontramos que los actores políticos y sociales han cambiado, lo cual introduce una dificultad tan básica como saber a quiénes se debe convocar y unir en torno a un nuevo proyecto, y cuál es la representatividad y fuerza de cada uno.

La segunda gran dificultad que señalábamos en un comienzo es lo que podríamos llamar el agotamiento del programa post noventa. Nuestro país vivió una transición sui generis: al momento del retorno de la democracia, el modelo neoliberal estaba "constitucionalizado" y la propia Constitución consagraba una democracia semisoberana que hacía imposible una modificación estructural. En esas condiciones, el entendimiento entre el centro y la izquierda — la Concertación — siguió un derrotero que tenía como foco la consolidación democrática, la búsqueda de la verdad y la justicia en derechos humanos, la disminución de la pobreza y la ejecución de otro tipo de reformas sociales dentro de los límites que ponía el propio modelo.

Este acuerdo programático de reformas que podríamos denominar intramodelo comenzó a tocar su techo cuando empieza a ponerse en el centro ya no el tema de la pobreza, sino que el de la desigualdad. La demanda de igualdad — unida a los problemas de abuso y de sobreendeudamiento - puso en evidencia, para una parte de la sociedad y de sus actores políticos, que no se podía seguir avanzando sólo dentro del pacto social transicional que algunos autores han calificado como "neoliberalismo corregido". Y que se requería un tipo de programa que, a lo menos, diera un tratamiento de ciudadanía y no de mercado a los derechos sociales. En el plano político-institucional, el binominalismo y su falta de competitividad fueron produciendo una oligarquización de la élite política que generó desconfianza y una crisis del sistema de representación política.

En este contexto, se produjo una suerte de "transición social por abajo", que estalló en 2006, 2011 y con distintas intensidades en los años siguientes. El modelo de gobernabilidad y gobierno transicional ya no era capaz de contener las diversas formas de malestar, incertidumbre y protesta presentes en la sociedad, especialmente en ese mundo social que el centro y, particularmente, la izquierda debían representar. En este sentido, lo que aquí sucede con el ala izquierda de la Concertación no es muy distinto de lo que ocurre con los partidos socialistas y socialdemócratas europeos, los que vieron alejarse a sus electorados, al no 
percibir diferencias significativas en comportarse entre las opciones de derecha y centroizquierda, principalmente en los ciclos de crisis.

Comienza a vivirse así al interior de la centroizquierda chilena una creciente bifurcación programática. En términos generales, podríamos caracterizar esta bifurcación entre persistir en la lógica de este "neoliberalismo corregido" o, bien, proponer un nuevo pacto político y social post neoliberal. Pienso que esta disyuntiva programática sigue dominando el escenario actual de la centroizquierda y que marcará su debate en el próximo período.

Una dificultad adicional para un entendimiento presente y futuro entre las izquierdas y un centro político de impronta socialcristiana es la creciente instalación de un clivaje en torno a temas valóricos o de "formas de vida", entre una visión más liberal que enfatiza la autonomía moral de las personas versus una más conservadora de inspiración religiosa, fundada en una idea de moral natural inmutable.

Por último, dentro de las dificultades para un rearme de un pacto entre las izquierdas y el centro, podríamos señalar un conjunto de cálculos de conveniencia que hoy rondan los partidos de este sector y que dificultan un acercamiento y la conformación de acuerdos. Esto puede verse especialmente presente en la DC, que recela de cualquier coalición con el Partido Comunista (PC) y el FA. Otro tanto ocurre con el FA en relación con la ex Nueva Mayoría (NM). En la medida en que se han articulado identidades en oposición a otras dentro del espacio de la centroizquierda, los acercamientos no son fáciles. En este contexto, surgen creativas fórmulas de "geometría variable" o de "círculos concéntricos"; es decir, de formas unitarias en distintos niveles, pero tampoco existe acuerdo sobre quiénes debieran integrar cada uno de esos distintos círculos. Esta indefinición no resistirá mucho más tiempo, y se requerirán próximamente definiciones en materia de política de alianzas mucho más precisas.

Este cálculo de crecimiento o decrecimiento futuro de cada organización política puede parecer menor al lado de los otros cambios aquí descritos, pero suele ser uno de esos factores no explicitados que más condiciona los comportamientos y decisiones de los actores políticos. Sin dar con fórmulas en que todos tengan la expectativa que podrán seguir creciendo o a lo menos no retroceder, será muy difícil establecer coordinaciones mínimas y alianzas. 
Hasta ahora hemos examinado las dificultades o las fuerzas centrífugas dominantes dentro del campo de la centroizquierda. El análisis da cuenta de dificultades profundas para pensar en una rearticulación en el corto plazo. Sin embargo, no se trata de dificultades insalvables. La unidad entre la izquierda y el centro tiene un camino que recorrer, quemar ciertas etapas. ¿En qué tiempo ocurrirá todo esto? No es fácil preverlo, pero no tiene por qué ser en el largo plazo. Los desafíos descritos son importantes, pero las diferencias y complejidades al interior de la centroizquierda no son mayores hoy que en otros momentos históricos.

El punto más crítico es un factor que sólo hemos mencionado al pasar: la confianza. Lo que más dificulta hoy una convergencia dentro de la izquierda - y luego de ésta con el centro - es la desconfianza que existe entre sus diferentes componentes. La forma como se eligió el abanderado presidencial de la ex NM en la elección pasada debilitó confianzas entre diversos actores, deshizo un tejido construido por décadas. El tema no fueron las decisiones mismas que se adoptaron, sino, sobre todo, la forma en que se hizo. Pero también existen nuevas desconfianzas, por ejemplo, del emergente Frente Amplio hacia la ex NM. Tampoco habría que minimizar las desconfianzas generacionales. Por otra parte, en el campo de la centroizquierda chilena se vive un recambio de sus élites, y ello siempre trae conflictos y deja heridos, y entre estas nuevas dirigencias aún no se han establecido las complicidades que marcaron a la élite anterior.

En definitiva, lo que uno puede concluir es que el mundo de la centroizquierda tiene mucho trabajo por delante. Su situación tiene algo de un nuevo comienzo, de asumir que la página está en blanco. Es un proceso que ha vivido en otros momentos de su historia. Requiere tiempo, muchas conversaciones formales, pero sobre todo informales; hay un proceso de maduración que no se puede acelerar artificialmente. Las elecciones uninominales de alcaldes y de gobernadores regionales, sin duda, acelerarán la necesidad de acuerdo y la búsqueda de fórmulas de alianzas. La elección de alcaldes con segunda vuelta puede ser virtuosa en este proceso reconstructivo, en el que se deberá poder combinar momentos de competencia y colaboración.

Por cierto, el futuro de la centroizquierda dependerá también de lo que sea capaz de hacer el actual gobierno. Y el gobierno luego de cien días sigue en deuda. No logra encontrar el tono ni articular una agenda 
de cierta trascendencia que permita percibir cuál es su sello. Algunas apuestas estratégicas de relegitimación del modelo dentro del modelo, y del empresariado como actor social, no muestran mayores avances. Se ve al gobierno lento y errático. En este sentido, y siendo realista, no me parece que esté escrito que la derecha deba necesariamente gobernar un próximo período. Comienza a avizorarse una baja en las encuestas, y auguro una abierta y competitiva próxima elección presidencial y parlamentaria en 2021. EP 